\title{
De como e quando se pode ler um enjambement
}

Filipe Manzoni

UFSC

\begin{abstract}
Resumo
Nosso trabalho se propóe a um mapeamento das dificuldades que decorrem de uma leitura da produção poética de Caio Meira a partir de uma instância de oposição entre verso e prosa. Num primeiro momento, nos voltaremos para os problemas que decorrem de uma teoria do verso pautada por uma supervalorização do enjambement, a partir da qual a produção de Caio Meira se coloca como eminentemente problemática. Em seguida, nos voltaremos para a leitura de um segundo cenário de análise a partir de um poema específico de Caio que parece deixar rastros de uma teoria própria do verso, mas que se torna igualmente problemática conforme propomos uma dinamização do seu contexto de leitura. Finalmente, nossa investigação nos conduzirá, em seus dois principais impasses, a uma prevalência de um gesto de leitura sempre sujeito ao contingente e acidental.
\end{abstract}

Palavras-chave: Caio Meira; Enjambement; Poesia e prosa.

\begin{abstract}
This research aims to canvass the problems of a critical investigation of the works of Caio Meira through an opposition of verse and prose. First this paper will focus on the problem of a verse theory that make the enjambement its sole criterion, what would make the production of Caio Meira become somehow paradoxical. Then, this research will focus on a specific poem of Meira, in which a verse theory becomes equally problematic as long as the pragmatic context of reading changes. Finally, this investigation will conclude with an intersection of both the previous topics in the form of a predominance of the potentiality of the gesture of reading, in all of its contingent matters.

Mots-clés: Caio Meira; Enjambement; Poetry and prose.
\end{abstract}


1 MEIRA, Caio. Coisas que o primeiro cachorro na rua pode dizer, 2003.

\section{Caio em A5: a ferramenta errada para um trabalho simples}

A inquietação da qual partiremos tem sua origem em um problema de ordem prática: a necessidade de transcrever os poemas de Caio Meira em uma folha de tamanho A5 para uma publicação acadêmica. Os versos de Caio, em especial desde seu segundo livro, Coisas que o primeiro cachorro na rua pode dizer, ${ }^{1}$ são, em geral, ligeiramente maiores do que as margens A5 permitiam em uma fonte em tamanho legível, de maneira que uma ou duas palavras sempre ultrapassavam o limite da página e eram forçadas para o verso seguinte, arruinando, portanto, qualquer leitura que levasse em conta os enjambements de seu poema (salvo se o final do verso fosse mantido alinhado à direita, dentro de colchetes, o que seria inviável pelo fato de serem todos os versos que teriam que ser quebrados dessa maneira, mudando completamente a disposição gráfica do poema).

O problema ainda se torna mais interessante quando buscamos, movidos pela curiosidade de como esse problema foi resolvido nas diferentes ediçôes do poeta, cotejar os enjambements dos poemas que foram publicados mais de uma vez. De fato, não apenas os versos de Caio são "ligeiramente maiores" do que uma margem em A5, mas os seus limites parecem ser dados, precisamente, pelas características gráficas da edição. Diferentes ediçôes de alguns poemas mostram uma diferença padrão em todos os seus enjambements: todos os versos têm o seu "fim" deslocado em uma ou duas palavras para frente ou para trás, indicando, em última instância, que não se trata tanto de um enjambement poético, mas sim do fim de uma linha.

Essa dificuldade de distinguir um "verso" de uma "linha" não é, porém, nenhuma novidade, sendo uma questão recorrente em qualquer manual de versificação nos tópicos concernentes ao verso livre, no qual, frequentemente, os limites entre poema e prosa se confundem. Nosso problema inicial de diagramação dos poemas de Caio revelaria, nesse contexto, um embaraço decorrente do erro de tratarmos como "poema" (buscando ler um instituto estritamente poético, o enjambement), uma produção incompatível com a própria categoria do "verso".

Esse embaraço ainda se desdobra em uma dupla alternativa com implicaçóes divergentes. Se priorizamos os enjambements, sabendo que estes sáo deslocados nas diferentes ediçóes do poeta, nos encontramos na curiosa constatação de que, a cada edição de Caio Meira, teríamos novos poemas, composto por versuras diferentes que permitiriam outras interpretaçóes. Se ignoramos os enjambements, lemos sua produção como se fosse prosa, resolvendo o problema da variedade de versóes, mas perdendo a possibilidade de ler as ambiguidades geradas pela quebra do verso/linha, além de irmos contra a própria designação do livro como de "poemas". 
Entre essas duas alternativas extremas é que cabe situarmos nossa própria tentativa de leitura. Nos interessa não tanto multiplicar versôes ou pacificá-las como variaçóes de um mesmo poema em prosa, mas sim explorar as consequências teóricas desses limites. No que toca à problemática dos enjambements, nossa proposta de leitura poderia ser traduzida como uma tentativa de desdobrar as consequências teóricas de utilizarmos, forçosamente, um aparato crítico inadequado para um trabalho simples: o que acontece se nos propomos a ler e dar sentido aos enjambements de Caio Meira, ainda que eles sejam talvez apenas uma consequência do trabalho de diagramação de suas obras?

A partir dessa inquietação de caráter mais formalista, uma segunda alternativa de investigação se colocará a partir de uma busca de um questionamento do limite entre prosa e verso a partir de um poema específico de Caio Meira que parece traçar, internamente, um limiar razoavelmente definido entre essas duas instâncias. Nos deteremos, assim, em uma tentativa de dinamização desse limite a partir de um superinvestimento dos erros e das contingências às quais o movimento de leitura está sujeito.

Se a inquietação da qual partimos, a impossibilidade de diagramar os poemas em A5, é, em última instância, uma curiosidade circunstancial, nossos dois caminhos de leitura se pautarão por uma insistência, talvez teimosa, em um caráter circunstancial do limite prosa/verso, o que nos levará, finalmente, em nosso tópico final, a uma reformulação da questão nos termos de uma política de leitura. Os limites entre poesia e prosa se colocarão, portanto, como mediados por uma potência sempre aberta ao inesperado, sempre sujeita a erros, impasses e falhas na tentativa de ler (ou de diagramar em formatos diferentes) a produção de Caio Meira.

\section{Quando é um enjambement?}

A centralidade que o enjambement assumiu nas reflexôes contemporâneas sobre o verso possui um marco inicial razoavelmente inequívoco: as reflexôes de Giorgio Agamben em "Ideia da prosa". ${ }^{2}$ O curto texto de Agamben é taxativo desde seu primeiro parágrafo:

nenhuma definição do verso é perfeitamente satisfatória, exceto aquela que assegura a sua identidade em relação à prosa através da possibilidade do enjambement [...] é, sem mais, poesia aquele discurso em que é possível opor um limite métrico a um limite sintático [...] e, prosa aquele discurso no qual isso não é possível. $^{3}$
2 AGAMBEN, Giorgio. Ideia da prosa, 2012 [1985], p. 29-32.

3 Ibidem, p. 29. 
4 Ibidem, p. 32.

5 MEIRA, Caio. Coisas que o primeiro cachorro na rua pode dizer, 2003.

6 Ibidem, p.26.

7 MEIRA, Caio. Romance, 2013.

8 Ibidem, p. 75.
O núcleo constitutivo do verso estaria, portanto, segundo Agamben, não em seu início, mas em seu fim: na possibilidade de oposição entre o elemento métrico e o elemento sintático, entre ritmo sonoro e sentido, ou ainda, em uma retomada de Benveniste, entre a série semiótica e a série semântica. Nessa oscilação, a versura (o fim do verso) se colocaria como um traço de radical ambivalência: ao mesmo tempo em que afirmaria a identidade do verso, apenas o faria a partir de uma "íntima discórdia”. Agamben nos diz: "é um gesto ambíguo que se orienta ao mesmo tempo para duas direçôes opostas, para trás (verso) e para diante (prosa). Essa suspensão, essa sublime hesitação entre o sentido e o som, é a herança poética que o pensamento deve levar até o fim.” ${ }^{4}$

Tomemos, agora, um exemplo da poesia de Caio Meira antes de prosseguirmos, os últimos três versos - evidentemente a própria categoria de "verso" como uma unidade contável é, no mínimo, imprecisa para nossa análise, mas cabe preservarmos por questóes práticas - do poema "Ornitorrinco", publicado em Coisas que o primeiro cachorro na rua pode dizer. ${ }^{5}$ Em sua primeira versão, publicada em 2003, lemos, no fechamento do poema: "e se decidirem que a vida faz mal à vida e o mundo estiver por um fio (se / digitados os códigos certos), pelo menos deixem-me perpetuar o segredo / de algumas misturas" ${ }^{6}$

Se empreendermos uma leitura priorizando o corte dos versos, temos, no primeiro enjambement, "e o mundo estiver por um fio (se", uma espécie de suspense extremo, na medida em que a condição para salvar o mundo é mantida apenas em sua partícula condicional "se", isto é, a condição propriamente dita apenas aparece no rejet "digitados os códigos certos". No que toca ao segundo enjambement, temos ainda a possibilidade de uma ambiguidade, na medida em que, se tomamos "o segredo" sem seu complemento "de algumas misturas", a ausência de delimitação parece torná-lo, em sua imprecisão, ainda mais secreto.

Se nos voltarmos, porém, para a republicação do poema em Romance, ${ }^{7}$ encontramos a seguinte disposição dos últimos três versos: "e se decidirem que a vida faz mal à vida e o mundo estiver por / um fio (se digitados os códigos certos), pelo menos deixem-me / perpetuar o segredo de algumas misturas." ${ }^{8}$ Não possuímos mais, nessa nova disposição, a suspensão da partícula condicional isolada. Em seu lugar, temos o isolamento da preposição "por” (com um efeito consideravelmente menos dramático). Quanto ao segundo corte, abre-se, na nova diagramação, uma curiosa ambiguidade: "deixem-me", quando isolado no final do verso, desloca-se de sua acepção única de "receber permissão ou ser autorizado", e passa a poder assumir também o sentido de "ser abandonado ou libertado". "Se o mundo estiver por um fio, deixem-me" parece levar a uma espécie de isolamento do sujeito 
frente à iminência da catástrofe, diferentemente do resguardo em uma tarefa derradeira.

O deslocamento do enjambement para palavras adjacentes nos abre, nesse sentido, possibilidades de ambivalências valiosas nos poemas de Caio, gerando uma miríade de sentidos alternativos que subjazem como alternativas potenciais, oscilaçôes diferentes entre a série semiótica e a série semântica. Esses deslocamentos, porém, mais do que ser uma excepcionalidade da poesia de Caio, é o que definiria a radical ausência de enjambements, isto é, a escrita em prosa, na qual o que define o final da linha é a margem da página e não um limite métrico.

Nesse ponto, isto é, quando não sabermos se o enjambement existe ou não, nos encontramos como que numa inversão da teoria agambeniana. Sua premissa estritamente formal ${ }^{9}$ de que o núcleo constitutivo do verso é o seu fim apenas se aplica na medida em que o enjambement é, ainda que enquanto potência, autoevidente: se ele é possível, estamos lendo um poema, se ele não é possível, trata-se de prosa. A partir do ponto em que não sabemos se ele é ou não possível, a impressão que temos é que é a proposição de um texto como "poema" o que em primeiro lugar nos oferece a possibilidade de ler o enjambement. Esse "instituto poético" seria, nesse sentido, mais um produto de um tipo de leitura (a leitura de poemas) do que um marco formal preciso.

Em outras palavras, se Agambem propóe a possibilidade do enjambement como opositor "perfeitamente satisfatório" entre prosa e verso, ele não nos diz quem é que dá essa possibilidade. Aparentemente, no caso da poesia de Caio Meira, não é o "poeta" quem determina o "núcleo constitutivo" do verso, mas sim o diagramador, e não por uma escolha que priorize este ou aquele corte, mas sim por critérios diversos, de maneira que o corte dos versos parece ser não mais do que uma consequência acidental do projeto gráfico do livro.

Nosso problema inicial com a poesia de Caio Meira se desdobra, assim, nos termos de como decidimos lê-la. A insistência em uma delimitação entre prosa e verso pelo argumento puramente formal do enjambement nos direciona a uma tomada de decisão ou a uma política de leitura: ou assumimos, em primeiro lugar, que a produçáo de Caio se trata de prosa e descartamos os enjambements, ou decidimos lê-la como poesia dando sentido aos cortes contingentes de seus versos. O que definiria, nesse sentido, os versos de Caio como versos náo seria uma categoria formal ou a vontade autoral, mas sim o gesto de leitura de reconhecer sua produçáo como em versos (e, portanto, ler nela a possibilidade de enjambements). Deixemos esse cenário de lado por ora, e nos voltemos para um poema que nos permitirá reencontrar, em um contexto diferente, algumas das mesmas questões.
9 Não foram poucas as releituras e desdobramentos pelos quais a proposta de Agamben passou desde sua proposição em 1985. Caberia ressaltar, nesse sentido, a proposição de Pierre Alferri, que critica essa "prática obstinada do corte e do enjambement à custa de qualquer outro sinal de reconhecimento do verso" (ALFERRI, Pierre. Rumo à prosa, 2003 [1994], p. 179-186) como sintoma de uma “assombração" da prosa. Se seguirmos Alferri, a poesia sempre tende ao prosaico, não tendo motivos uma distinção precisa. O próprio Agamben retornaria ao mesmo tópico, dez anos depois, em "O fim do poema” (AGAMBEN, Giorgio. O fim do poema, 2014 [1995], p. 179-186), voltando-se para o problema que o último verso traria para a questão: "se o verso é definido pela possibilidade do enjambement, segue-se daí que o último verso de uma poesia não é um verso" (Ibidem, p. 182). Nesse contexto, parece interessar mais ao filósofo italiano desdobrar, da poesia, uma tendência natural a desembocar na prosa filosófica. Num contexto mais recente, caberia ainda ressaltar as proposições de Florência Garramuño, que prioriza uma indecidibilidade entre prosa e poema, uma "inespecificidade" entre essas duas instâncias, ou um "passo de prosa" como operador de leitura da produção contemporânea (GARRAMUÑO, Florência. $\mathrm{O}$ passo de prosa na poesia contemporânea, 2014, p. 49-82). De fato, o "passo de prosa” de Garramuño parece falar diretamente ao nosso impasse inicial com a poesia de Caio, quase que "resolvendo" nosso problema como uma investida num "deslimite" entre prosa e poema na produção do autor. Cremos, porém, que a insistência no caráter formal da distinção de Agamben (do qual Garamuño se afasta) nos permite desdobrar algumas consequências curiosas da priorização do enjambement, conforme abordaremos. 


\section{De como e quando se descobre uma via de duplo sentido}

"De como e quando se descobre uma falcatrua" é um poema de Caio Meira publicado originalmente em 2003, em Coisas que o primeiro cachorro na rua pode dizer. Trata-se do segundo poema mais longo de Caio, embora uma contagem de "versos" como critério pareça evidentemente inadequada. O poema ainda foi republicado duas vezes, incorporado à coletânea Inquietação guia: 15 poetas em torno da Azougue, de 2009, e integrado à edição da poesia reunida de Caio em 2013, Romance.

A diagramação do poema muda consideravelmente de uma edição para outra, movimentando a maior parte dos enjambements de lugar, além de outras diferenças gráficas, como a marcação de alguns trechos em itálico (precisamente os que se propóem como rascunho de um poema por fazer, conforme veremos). Optamos aqui pela transcrição de sua primeira versão, de 2003, mas sinalizaremos as diferenças mais significativas, conforme elas forem aparecendo em nossa leitura. Tomemos o poema:

\section{De como e quando se descobre uma falcatrua}

Maio acontece em seu corpo, enraizando-se, enchendo suas pálpebras de azul e de frio aquoso. O grito mais moderno, propagado por alto-falantes e em letras garrafais, ainda vibra em seus tímpanos: não, ele não deseja comprar nada, não quer saber das teorias da apropriação, nem da atração do metal e das demais virtudes capitais ao sucesso. Quando perambula pelo centro, como agora, mesmo parando de vitrine em vitrine, quer mais é perder-se entre cores eformas, infiltrar-se de abismos. Está certo, quando finalmente chegar em casa, terá de fazer isso e aquilo, consertar a dobradiça da porta, digitar a cota de todo dia, cada toque vale $\mathrm{R} \$ 0,007$, distribuir broncas e beijos entre os filhos, preocupar-se com o não-andamento de teses, livros, resenhas e demais promessas. Na rua, porém, o caminho mais longo entre dois pontos é sempre uma manchete revoltante, uma nova edição da senhora H., um cabo de guarda chuva diferente. Emtra numa loja e pergunta se tem o cd novo da Suzanne Vega, ou um antigo da Diana Krall; não, não tem, já sabia disso. Ele até deseja comer uma esfirra, tomar uma coca-cola, mas está tentando fazer uma dieta, perder 5 quilos. Passa direto. Pensa que ter fome por algumas horas é até divertido, pois dá para sentir o estômago vivo. Enquanto caminha, vai repassando na cabeça algo que pretende escrever quando chegar em casa:

maio entreaberto num dia de chuva (esse é o título)

nada além do tempo me procura

sentado num banco num afã do centro da cidade

a contrapelo da balburdia, do ruido das entranhas, minhas ou do metrô

nada me perfura, nem astúcia ou turra

só o murro lento do que passa e acumula no bulício impalpável de visceras 
e nas tábuas verdes atravessadas sob as nádegas, a sustentação dos ossos e dos músculos encorpando o vazio

nada me distingue do pleno, do jorro de pedra da boca dos leóes

desertado de gente e carro

nada me enxerga em ambos os lados da retina

nenhum susto nem intercessáo entre ritmos de rodas, de asfalto, sêmen e de lixo atirado na calçada

nada perdura, arvorado, neste banco pintado de verde

só a chuva

mas que importa, trajes, carapuças, tatuagens, certidóes, constipação ou a cor do desalinho

mas que importa a memória e suas pipas, balóes, livros já sem sabor,

a empunhadura genital

nada conspira, nenhuma trama

só mesmo a água

e a infima areia passageira do vento

Mas tem dúvidas, fica pensando se não está lírico demais, fundado em imagens, e ele está fugindo de imagens em poemas, anda atrás das coisas mais palpáveis, sólidas. Quando chega ao edifício Marquês de Herval, resolve dar um pulo no Beringela, ver se tem a Carta ao pai do Kafka. Um dia ele também vai ter de escrever uma carta a seu pai que, apesar de morto, ainda o assombra. Não tem. Espia entre as novidades. Não, alguém passou por ali antes dele. Sai. Subindo as escadas em caracol, outro fragmento lhe vem à mente, daqueles que não se resolvem, mas que também assombram (talvez ele possa inseri-lo em algum lugar):

dentro do ônibus que atravessa a Rio Branco

dentro da velocidade e da freada

dentro do troco

acordado, alimentado, envelhecendo com todas as juntas, com as arruelas, com a napa preta do banco

com o braço cansado do motorista, com a estridência do motor

em rotação e translação

até chegar à Praça da Bandeira e incerto descer

vendo o ônibus se afastar

separar-se de meus sentidos

do fígado, dos intestinos, da digestão e da fome

e caminhar a pé até em casa

Quem sabe se entrar de fato num ônibus na Rio Branco, qualquer ônibus, sem se preocupar com o destino, ele consiga continuá-lo, ou abandoná-lo de vez... Só então se dá conta da incongruência: quem pega ônibus na Rio Branco não pode estar indo à Praça da Bandeira, pois é a direção oposta.Apesardeparecer pouco importante, issoo incomoda. Quandofoi que inventou um absurdo daqueles? Para ele, é mais uma prova cabal de desonestidade, de que precisa ir mais fundo, cavar nas entranhas algo mais genuíno, que não pegue um ônibus inexistente, que não tome uma direção falsa. Então entra num táxi e diz ao motorista: "Praça da Bandeira, por favor”. É a sua maneira de ser mais honesto. ${ }^{10}$
10 MEIRA, Caio. De como e quando se descobre uma falcatrua, 2013, p. 43-46.

Se nosso impasse inicial era no sentido de ler ou não a produção de Caio Meira como poesia, "De como e quando se descobre uma falcatrua" se 
torna um ponto especialmente problemático. Inserido no bloco central de Coisas que o primeiro cachorro na rua pode dizer - "Outras vidas: a mesma", no qual todos os poemas investem pesadamente em uma aproximação para com a prosa -, o "poema" apresenta uma narrativa do processo de rascunho de um poema, "maio entreaberto num dia de chuva", transcrito (ao menos parcialmente) no corpo de "De como e quando se descobre uma falcatrua".

O limite entre a prosa e o verso é, de certa maneira, evidente: os trechos mais fortemente narrativos do poema se estruturam como grandes parágrafos, sem indicação de cortes em unidades menores. Já os trechos que constituem o poema rascunhado se colocam dispostos em unidades menores (estas que já foram apontadas por Alberto Pucheu como versos de "fôlego largo"), ocasionalmente maiores que uma linha, mas predominantemente menores; destacadas do corpo em prosa do poema pela fonte em itálico. Esses versos parecem ainda constituir unidades distintas, na medida em que há uma diferença de espaçamento entre os versos que possuem uma continuidade em mais de uma linha e os que aparecem sozinhos.

Tudo leva a crer, nesse sentido, que Caio nos propóe um corte bem delimitado entre poema e prosa (apesar de a diferença da fonte em itálico não aparecer na versão mais recente do poema, em 2013, na qual a diferenciação entre prosa e verso é feita por um recuo no alinhamento à esquerda dos versos). Se cotejarmos, porém, tanto a "prosa" quanto os "versos" de "De como e quando se descobre uma falcatrua" com outras versóes do poema, fica evidente o quanto essa delimitação não deve nada a possibilidade ou não do enjambement. Todos os trechos do poema possuem deslocamentos (em geral de uma ou duas palavras adjacentes) no ponto em que são cortados pela página em diferentes ediçóes, tanto no poema rascunhado e transcrito quanto na narrativa de sua escrita.

Tudo se passa, nesse sentido, como se Caio indicasse de maneira quase didática onde o poema é "prosa" e onde não é (ou, ao menos, onde não é tanto), mas não mostrasse nenhum limite formal preciso para isso. O limite parece se colocar no plano de uma diferença de discursividade que poderia ser observada a partir de uma contraposição na forma como alguns fatos comuns às narrativas "em prosa" e "em verso" são colocados: a sobreposição de elementos prosaicos da paisagem urbana, andar de vitrine em vitrine, ler manchetes revoltantes, ou observar cabos de guarda-chuva diferentes se transforma, no poema, em "a contrapelo da balbúrdia"; o "pensa que ter fome por al-/gumas horas é até divertido, pois dá para sentir o estômago vivo" se torna "do ruído das entranhas, minhas ou do /metrô". De fato, parece haver uma continuidade imprecisa entre as duas cenas, a da narrativa e a do poema: em ambos os trechos estamos em Maio, no centro da cidade do Rio 
de Janeiro, em um dia de chuva, embora esse cenário seja construído por recortes diferentes: no poema, o sujeito está sentado em um banco e, em seguida em um ônibus; no trecho em prosa, está perambulando por lojas e vitrines.

Se as cenas são semelhantes, a inquietação central de "De como e quando se descobre uma falcatrua" se coloca precisamente como uma recusa de um lirismo "falsificante" que operaria no "poema interno", um afastamento da realidade tátil e "palpável”. Isso é posto de maneira evidente quando, após o fragmento final do poema, no qual o personagem encontra-se em um ônibus na Avenida Rio Branco a caminho da Praça da Bandeira, a voz "em prosa” constata a impossibilidade pragmática de tal percurso, já que a Avenida Rio Branco apenas tem seu fluxo no sentido Presidente Vargas Cinelândia.

O choque da constatação é interessante porque parece jogar com uma dissociação entre os trechos "em versos" dos trechos "em prosa", como se os versos se mantivessem em um nível imaginativo enquanto a prosa se mantivesse fiel ao pragmático. Essa desonestidade, respondida com o gesto de pegar um táxi em direção à Praça da Bandeira, situado no nível do "real" e não imaginativo, é, precisamente, o drama da constatação de uma dissociação entre prosa e verso ou ainda entre vida e literatura. A busca declarada de que o poema invista nas coisas mais palpáveis, concretas, se desmascara, assim, no trecho em prosa, como se a instância que diferenciasse verso e prosa fosse mesmo uma tentativa sempre frustrada daquele de se aproximar do contato e das coisas "prosaicas" desta.

Nada mais sintomático nesse sentido do que o fim do poema de Caio. Se o corte que diferencia o poema da prosa se coloca como um grau de afastamento da experiência pragmática, limite contra o qual a poesia luta "buscando coisas mais palpáveis", trata-se de um limite contra o qual o próprio biográfico esbarra também, na tentativa desajeitada de pegar um táxi para fazer a rota do ônibus inexistente. O drama interno que separa e aproxima poesia e prosa não se coloca tanto nos termos de uma oposição entre o semiótico e o semântico, mas sim entre o semântico e o pragmático (e biográfico). A tentativa de redimir a distância entre vida e literatura, essa falcatrua, apontaria, finalmente, para uma concepção da poesia que falasse de uma experiência do cotidiano mais genuína, imediata e palpável. Trata-se de uma proposta um tanto idealista, que parece circunscrever o "real" ou o pragmático a um estatuto específico, a ser buscado e retratado pelo poema/ prosa.

Um fato curioso, porém, nos permite (talvez contrariamente à proposta do próprio poeta) reformular a questáo. No momento em que "De como 
e quando se desdobre uma falcatrua" foi publicado, o sentido da Avenida Rio Branco era único: precisamente, o sentido oposto de quem quisesse ir à Praça da Bandeira. Porém, entre 8 de fevereiro de 2014 e 29 de novembro de 2014 (após a reformulação dos itinerários dos ônibus no centro do Rio de Janeiro e antes do início das obras da prefeitura para a construção do veículo leve sobre trilhos, VLT), a Avenida Rio Branco foi, efetivamente, uma via de mão dupla.

Dentro de uma janela de pouco menos de 10 meses, o fato que comprova a dissociaçáo do real e que dá a diferença entre poesia e prosa no poema de Caio estava invertido. Se nos situamos, hipoteticamente, como leitores dessa época, a questão se reconfigura de maneira que o verso é o que está mais colado à realidade e às coisas palpáveis, e a prosa é o que destoa da experiência pragmática.

Mais do que propor cenários nos quais o "pragmático" muda de lugar, o que nos interessa é observar o quanto o "mais palpável”, isto é, o que diferenciaria poesia de prosa, não é uma qualificação valorativa estática - da qual decorreria um critério escalar do mais ou menos poético, mais ou menos pragmático - mas um estatuto dinâmico cuja possibilidade de verificação se reprocessa a cada gesto de leitura. Novamente nos situamos, portanto em um paradigma no qual a mediação entre prosa e poema se coloca pelo contingencial (afinal, talvez a Avenida Rio Branco volte ainda a ser mão dupla em alguns anos) da reatualização de um gesto de leitura.

As instâncias que oporiam, nesse sentido, verso a prosa, parecem se desarmar, nos dois cenários que observamos da poesia de Caio Meira, por um caráter contingencial. Se tomamos, como faz Agamben, a possibilidade do enjambement como critério de oposição entre prosa e verso, a poesia de Caio nos responde com um corte de versos que é resultado acidental das escolhas diagramáticas de sua obra (tamanho do papel, da fonte, espaçamento, etc.). Se seguimos Caio (e toda uma tradição que parece associar a poesia a um caráter aurático) e flagramos no verso uma dicção mais idealizada, historicamente mais dissociada do real do que a "prosa do mundo", a impossibilidade de determinação de um "real" frente a suas mudanças fenomênicas relativas aos diversos movimento de reatualizaçáo de leitura embaralha novamente a questão (isto é, de certa maneira, as obras da prefeitura do Rio de Janeiro ensinam a ler de maneira desviada o poema de Caio Meira).

Nossa investigação, nesse sentido, da oposição entre verso e prosa não parece levar, na poesia de Caio Meira, para uma dissolução da oposição entre os dois discursos, mas sim para sua mediação pelo contingente. Não se trata de saber $o$ que é o verso ou prosa ou em que medida essas instâncias se confundem, mas sim de descobrir como e quando esses escritos seriam versos 
ou prosa, o que nos direciona para uma temporalidade e uma modalidade acidental agenciada por diferentes gestos de leitura.

Fica evidente ainda o quanto nos distanciamos, nesse percurso, de qualquer delimitação de prosa e verso que dependa de um lastro autoral. Ao deslocarmos o gesto de leitura para levar em conta o cenário no qual a Avenida Rio Branco foi uma via de duplo sentido, nos afastamos do vínculo do poema com um contexto único e irrepetível de sua escrita por um "autor" e fazemos com que o "real" ou o "mais genuíno" esteja sujeito ao acidental. No que toca aos enjambements, tomá-los como contingentes nos permite multiplicar, conforme nos deslocamos entre diferentes ediçôes existentes ou imaginadas, ambiguidades outras, disseminando sentidos possíveis não planejados. Curiosamente, se desdobrarmos nossa discussão teórica agambeniana para um último contexto, chegaremos a uma reformulação possível para esses mesmos dois tópicos.

\section{Parataxe}

Nosso percurso pelo questionamento de um limite entre prosa e poesia na produção de Caio Meira nos levou a dois contextos de alguma maneira paradoxais: primeiramente, a impossibilidade de fundar um limite entre prosa e verso segundo uma teoria que priorize o enjambement, na medida em que o fim do verso é mediado em diferentes versóes dos poemas do autor pela contingência prática da diagramação; e, em segundo lugar, a igual impossibilidade de flagrarmos um limite entre verso e prosa que se pautasse por um resíduo aurático do poético (ou um afastamento autonomizante do real) pelo fato de esse vínculo com o "real", uma vez que mediado por um movimento de leitura, se dinamiza e se torna também acidental. Nos dois impasses a questão que se coloca é uma espécie de política de leitura, isto é, na possibilidade de darmos sentido a deslizamentos acidentais e não necessariamente a escolhas lastreadas pela figura de um "autor".

Curiosamente, se retomarmos as investigaçóes de Giorgio Agamben sobre uma teoria do verso a partir de um ponto diferente, encontraremos alguns rastros que falam diretamente a nossos impasses. Se nos pautamos, até aqui, pelas definiçôes taxativas de "Ideia da prosa" ${ }^{11}$ cabe agora nos voltarmos para algumas reflexóes que aparecem em um excurso de $O$ reino e a glória. $^{12}$

Neste contexto, Agamben está tratando da produção tardia de Hölderlin, ressaltando nesta uma "fragmentação prosódica particular e feroz" ${ }^{13}$, isto é, o rompimento radical com a forma métrica nos últimos hinos
11 Caberia ressaltar que Agamben ainda se volta para essas questóes a partir de um paradigma teológico. A poesia se definiria, em sua prosódia clássica como um dispositivo temporal escatológico - do qual Agamben se ocupa em $O$ tempo que resta-que, após a despedida dos deuses, lida especificamente na poesia de Hölderlin, oscilaria entre uma ateologia ou uma teoalogia (que aparece na mesma nota de $O$ reino e a glória à qual nos voltaremos). O que nos interessa ressaltar é o quanto nosso interesse em uma prevalência da contingência parece se aproximar dessa teo-alogia proposta por Agamben. Não nos deteremos, porém, nos desdobramentos possíveis dessa associação.

12 AGAMBEN, Giorgio. O reino e a glória, 2011 [2007].

13 Ibidem, p. 259. 
14 Ibidem, p. 260.

15 Ibidem, p. 260. do poeta. Agamben retoma, para tanto, a sugestáo de Theodor Adorno, que já havia proposto que prevaleceria, nos hinos tardios de Hölderlin, a "parataxe" ou "articulação dura". Cabe retomarmos a paráfrase agambeniana, segundo a qual na parataxe

cada palavra se isola de seu contexto semântico até constituir uma espécie de unidade autônoma, enquanto, na articulação suave, as imagens e o contexto sintático subordinam a si e, ao mesmo tempo, conectam mais palavras. "A articulação dura faz tudo para exaltar a própria palavra, imprimindo-a no ouvido de quem a escuta e arrancando-a, na medida do possível, do contexto associativo das imagens e dos sentimentos a que pertencia”. ${ }^{14}$

A conclusão de Agamben é a de que na poesia tardia de Hölderlin "todo discurso e todo significado parecem fazer-se em pedaços e contrair-se em uma espécie de paralisia, a um só tempo prosódica e semântica", ${ }^{15}$ aproximada ainda, pelo filósofo italiano da extrapolação hínica que está em jogo na "suspensão vibrátil em relação ao seu contexto sintático" que caracterizaria a explosão vocabular de Um coup de dès de Stéphane Mallarmé.

Aqui chegamos ao ponto que nos interessa. A explosão da prosódia hínica lida por Agamben em Hölderlin faz com que, no limite, toda palavra seja um ponto possível de paralisia e oscilação entre as séries semióticas e semânticas (o que ainda seria maximizado pela explosão diagramática do poema operada por Mallarmé). O que é dizer que o estatuto que era próprio do enjambement deixa de ser apenas aplicável ao "fim do verso", mas opera dentro de cada fragmento possível deste. A potência do enjambement residiria, em última instância, em qualquer palavra, bastando que esta assim se "imprima no ouvido", isto é, que seja tomada dentro de uma operação interessada de leitura.

A leitura crítica se projeta assim em patamar completamente distinto de um desvendamento de um sentido (seja ele lastreado ou não pela instância autoral), mas se coloca como uma proliferação de sentidos possíveis a partir de equívocos acidentais. Ler enjambements, nesse sentido, onde eles aparentemente náo existem se coloca como uma modalidade de potencializar cada vez mais os equívocos de um poema, ou de explorar o que, na escrita, está sempre sujeito a erro.

Encontramos-nos, portanto, de volta com nosso primeiro cenário de leitura: se o fim dos versos de Caio Meira, isto é, a possibilidade de seus enjambements, não respeita uma fidelidade originária a uma instância autoral, 
mas se sujeita as contingências diagramáticas, nosso papel enquanto leitores críticos seria precisamente proliferar o quanto possível essas potencialidades outras, fazer ressoar essas "suspensôes vibráteis" para além do seu contexto sintático. No que toca ao nosso segundo tópico, isto é, a mobilização do "mais palpável" pelo movimento pragmático de leitura, cabe retomarmos alguns aspectos da própria proposição adorniana do conceito de parataxe.

Adorno se coloca, desde o início de seu texto precisamente contra o paradigma de interpretação como reconstrução de uma intencionalidade autoral. O que o interessa na produção de Hölderlin (que tenta "resgatar" da leitura heideggeriana) é uma "refração" dos nomes, isto é, o que nestes sempre resta como um "saldo daquilo que querem e não alcançam". ${ }^{16}$ Adorno ressalta e insiste nessa refração como uma "vida própria" (ou uma "segunda vida") dos nomes fundada pela "dissociação do imediato", ${ }^{17}$ isto é, por um cancelamento da ilusão de uma "conciliabilidade com o puro 'aqui e agora.".18

Nesse contexto é que a parataxe se torna importante, na medida em que no lugar da sintaxe subordinativa, composta pela lógica "dos períodos densamente fechados, que necessariamente desembocam nos seus complementos", ${ }^{19}$ àquela interessa precisamente uma "abertura de sentido" de natureza "arritmática" (o mesmo arrancar a palavra de seu contexto sintático associativo de que nos fala Agamben).

Voltemos ao fim de "De como e quando se descobre uma falcatrua". Caio propóe, no afastamento entre escrita e realidade pragmática, uma falcatrua, redimida pela corrida desajeitada de táxi até a Praça da Bandeira. De nossa parte, isto é, enquanto leitores, essa falcatrua está sempre aberta: enquanto o poema estiver sujeito à leitura, ele estará sujeito a erro, os nomes ainda estarão sujeitos à refração. Mais ainda, é precisamente continuar a refratar o poema e desdobrá-lo para outros contextos e outros sentidos equívocos que, nos parece, constitui a atividade crítica. Trata-se do ponto, em ultima instância, pelo qual recorremos a nossa metodologia algo caótica, priorizando um mecanismo crítico impróprio para potencializar a contingência do enjambement, proliferando, à revelia de uma intenção autoral, ambiguidades implanejadas.

A priorização dessa política de leitura não se coloca, nesse sentido, como resolução para qualquer de nossos impasses críticos, não resolve a impossibilidade de um limite entre verso e prosa em Caio Meira da mesma maneira que o trajeto de táxi rumo a Praça da Bandeira não redime a distância do poema com uma experiência real. De fato, nossa leitura se coloca, de certa maneira, como análoga à solução desastrada do poema de Caio, ou, talvez, como uma falcatrua semelhante. Se o trajeto de ônibus impossível
16 ADORNO, Theodor. Parataxe, 1991, p. 91.

17 Ibidem, p. 91.

18 Ibidem, p. 93.

19 Ibidem, p. 105. 
em 2003 se tornou possível em fevereiro 2014 e novamente impossível a partir de novembro, ser possível ou impossível é uma questão de diferentes contextos de leitura. Pluralizar cenas de leitura, portanto, de maneira de manter aberta a potencialidade de sentidos equívocos, se coloca não como uma saída das aporias, mas como uma maneira de ser mais honesto às suas possibilidades.

\section{Referências}

ADORNO, Theodor. Parataxe. In: Notas de literatura. Rio de Janeiro: Tempo Brasileiro, 1991.

ALFERRI, Pierre. Rumo à prosa. ALEA, v. 15/2, p. 423-427, Jul-Dez 2013.

AGAMBEN, Giorgio. Ideia da prosa. In: Ideia da prosa. Belo Horizonte: Autêntica Editora, 2012. p. 29-32.

AGAMBEN, Giorgio. O fim do poema. In: Categorias italianas: estudos de poética e literatura. Florianópolis: Editora da UFSC, 2014. p. 179-186.

AGAMBEN, Giorgio. O tempo que resta. Um comentário à Carta aos Romanos. Belo Horizonte: Autêntica Editora, 2016.

AGAMBEN, Giorgio. O reino e a glória: uma genealogia teológica da economia e do governo: homo sacer, II, 2. São Paulo: Boitempo, 2011.

GARRAMUÑO, Florência. O passo de prosa na poesia contemporânea. In: Frutos estranhos: sobre a inespecificidade na estética contemporânea. Rio de Janeiro: Rocco, 2014, p. 49-82.

MEIRA, Caio. Romance. Rio de Janeiro: Editora Circuito, 2013.

MEIRA, Caio. Coisas que o primeiro cachorro na rua pode dizer. Rio de Janeiro: Azougue Editorial, 2003.

MEIRA, Caio. Inquietação guia: 15 poetas em torno da Azougue. Rio de Janeiro: Beco do Azougue, 2009.

PUCHEU, Alberto. Uma poética da permeabilidade (a partir de um livro de Caio Meira). In: Pelo colorido, para além do cinzento. Rio de Janeiro: Beco do Azougue, 2007. p. 62-73.

Submissão: 30/09/2018

Aceite: $11 / 11 / 2018$

https://doi.org/10.5007/2176-8552.2018n25p57 